\title{
LA PESCA ARTESANAL EN EL SUR AUSTRAL DE CHILE. CONTROVERSIAS TERRITORIALES EN EL ESPACIO MARINO-COSTERO
}

\author{
Artisanal fishing in the far south of Chile. \\ Territorial disputes in the marine-coastal space
}

\section{GONZALO SAAVEDRA GALLO*}

Fecha de recepción: 26 de enero de 2016-Fecha de aprobación: 4 de abril de 2016

\section{Resumen}

El artículo analiza desde una perspectiva etnográfica tres casos en donde se evidencia que la dimensión territorial de la pesca artesanal, en el sur-austral de Chile, es problemática y compleja. Problemática porque revela que el uso/apropiación del espacio en cuestión es diverso y desigual según los actores que en él se sitúan. En tal escenario son las comunidades de pesca artesanal las que mayoritariamente padecen las consecuencias perversas de esta desigualdad, encontrando un lugar cada vez más incierto y vulnerable como forma de vida cultural. En contrapartida es un escenario atractivo para empresas e inversionistas privados, quienes se ven notoriamente favorecidos por los marcos regulatorios y legislativos impulsados desde la administración estatal. Es un escenario de complejidad porque se trata de territorios y sistemas económico-sociales abiertos, dinámicos y cambiantes, condición multidimensional que nos impele a pensar y problematizar el espacio pesquero artesanal más allá de sus emplazamientos convencionales (la caleta, la comuna o la región). El análisis que aquí se plantea explora las tensiones aparentemente internas que derivan del entramado relacional referido, las que sin embargo desbordan los límites de cada localización.

Palabras clave: Pescadores artesanales, Conflicto, Sur de Chile.

\begin{abstract}
This article applies an ethnographic focus to three cases in which we show that the territorial dimension of artisanal fishing in the far south of Chile, is problematical and complex. Problematical because we reveal that the use/appropriation of the space in question is variable and unequal for the different actors involved. In this scenario, it is mainly the artisanal fishing communities which suffer the cruel consequences of this inequality, with an increasingly uncertain and vulnerable space available for their culture and way of life. The other side of the coin is an attractive scenario for private investors and companies, who are strongly favoured by the regulatory and legislative frameworks promoted by the government. The scenario is complex because it affects open, dynamic, changing economic-social territories and systems, a multidimensional situation which leads us to consider and problematize the artisanal fishing space beyond its conventional locations (the port, the municipality or the region). In this analysis we explore the apparently internal tensions resulting from the above web of relations, which in fact extend beyond the limits of each location.
\end{abstract}

Keywords: Artisanal fishermen, Conflict, Southern Chile.

* Antropólogo, Universidad de Chile. Doctor en Ciencias Políticas y Sociología, Universidad Complutense de Madrid. Académico Instituto de Estudios Antropológicos, Universidad Austral de Chile. Correo-e: gonzalosaavedragallo@gmail.com 


\section{Introducción: Perspectiva económico-an- tropológica del sur-austral de Chile}

El sur-austral de Chile, geografía de sublimes e idealizados paisajes naturales, también es lugar de culturas milenarias (Reyes, San Román \& Moraga 2011) y espacio de vidas sociales en flujo y movimiento. El territorio se ha construido en una tensión recurrente entre dinámicas tradicionales y modernas. Los influjos vernáculos de la vida económica local encuentran sus anclajes en remotos, aunque extintos, sistemas de vida canoeros y luego, tardíamente, en lo que podríamos denominar las culturas económicas del bordemar. Estas culturas podrían ser descritas como sistemas de reproducción social de la vida material basados en la apropiación de la interfaz tierra-mar, integrando agricultura a pequeña escala, recolección de orilla y pesca artesanal (Skewes, Álvarez \& Navarro, 2012) ${ }^{1}$.

El constituyente identitario más decisivo de la economía costera de sur de Chile es el espacio bordemarino (Urbina, 1998). La expresión bordemar aparece con frecuencia en la literatura sobre Chiloé -principal referencia territorial de este trabajo-, y por lo general se asocia a unas formas de hacer, vivir y estar en el lugar que en parte nos recuerda que ese eje de identidad y diferencia se despliega en el mundo material, intersubjetiva y temporalmente, desde una compleja trama de representaciones, significaciones e ideas (Godelier, 1990). Lo anterior condiciona las relaciones de apropiación que los actores del territorio y en especial las comunidades históricas que allí habitan ejercen sobre el espacio en cuestión. En otras palabras, el valor simbólico del bordemar está dado por las representaciones y significaciones que sobre él han construido sus habitantes.
El bordemar puede observarse y entenderse como un espacio dialéctico y dialógico. Pero además es un espacio ideo-material, semántico en una concepción territorial contemporánea y de base cultural (Escobar, 2008). Es dialéctico y dialógico porque es social y al ser social es relacional. Sobre esta complejidad e hibridación, ocurre la interfaz comunidades locales (productores/extractores), mercado (o agentes del mercado) y agencia pública.

Las dinámicas relacionales de los actores siempre ocurren en un marco de cosmovisión que desborda cualquier materialidad. Bajo esta mirada el bordemar es polisémico y complejo. Polisémico porque sus significados varían de acuerdo a los actores que lo viven y apropian según criterios de localización y usos productivos diferenciados. Complejo porque se trata de un escenario de múltiples tramas relacionales, las que no solo incluyen interacciones entre sujetos sociales sino además entre los sujetos y el propio espacio costero, y también relaciones con agentes y dinámicas exógenas. A lo anterior habría que añadir una dimensión de historicidad, que permite esa apropiación espacial, y que tiene un factor de diferencia en tanto cada localización social presupone decursos temporales específicos, conectados o articulados a los tiempos de la modernización pero no del todo subsumidos en ellos (Valencia, 2009). En ese marco, cabe entenderlo además como un espacio de hibridación, de resistencia, de reformulación y de transgresión. 
El sur-austral, un escenario de constricciones modernizantes

El escenario del desarrollo pesquero-artesanal en el sur-austral chileno se encuentra jalonado por una notable avanzada del mercado en los últimos 30 años. Sobresale especialmente la proliferación de las industrias pesquera, salmonera y mitilicultora, todas en evidente articulación con los sistemas artesanales que desde tiempos remotos persisten en estas latitudes. Si bien este análisis no se centra en la relación entre industria y sistema artesanal, a modo de contexto económico-político el despliegue industrial y del mercado resulta fundamental, en particular si tenemos en cuenta los ejes del empleo, la producción y el ambiente, en donde evidentemente ha operado una transformación significativa y acelerada de los bordes costeros del sur-austral.

En este vasto territorio -uno de los más prolíficos a nivel nacional en capturas artesanales y en producción acuícola ${ }^{2}$ - se explotan pesquerías pelágicas y bentónicas, incluyendo algunas especies demersales como la merluza austral, sin embargo, paradójicamente se constata una marcada tendencia monoextractiva condicionada por los ciclos hidrobiológicos, la biodisponibilidad, las reglamentaciones que regulan el acceso a los recursos y cuotean sus capturas, y particularmente la demanda de los mercados a través de dinámicas de intermediación muy diversas y complejas.

Como punto de partida habría que reseñar el marco legislativo, definido en la Ley General de Pesca y Acuicultura (LGPA), que data de 1991 pero derivada de debates sostenidos en décadas anteriores (Bitrán, 1989). Este cuerpo legal fue determinante en dos aspectos relevantes: primero, ordenando las dinámicas extractivas en todas las escalas, y segundo, buscando mejorar la rentabilidad comercial de la actividad pesquera. Las principales medidas que, desde la administración estatal, favorecieron ese proceso fueron la regionalización de la pesca artesanal y la definición de los regímenes generales de acceso, incluyendo las Áreas de Manejo y Explotación de Recursos Bentónicos (AMERB), el Régimen Artesanal de Extracción (RAE) y los planes de manejo, de reciente incorporación en la LGPA.

Una figura administrativa, ideada y decretada para el incentivo empresarial, fue la concesión de acuicultura. El impacto de la política de concesiones fue de tal magnitud que en el curso de 10 años - desde fines de la década de 1990la cantidad de concesiones, otorgadas a empresas salmoneras y mitilicultoras ha saturado el mar interior de Chiloé y parte importante de los canales de Aisén, tensionando las relaciones entre comunidades locales, empresas y agencia pública. En la actualidad, pese a la crisis que afectó a la industria del salmón entre los años 2007 y 2009 (Anemia Infecciosa del Salmón o virus ISA y ralentización del mercado exportador), la tendencia al crecimiento -aunque más moderada- se ha mantenido ${ }^{3}$.

Frente a dos influjos de transformación modernizante bastante notorios y decisivos -la expansión del mercado, por una parte, y el despliegue institucional, formal y normativo del Estado por otra, debe destacarse, en primer lugar, que el bordemar como espacio configurador de sentido pesquero-artesanal desborda toda lógica instrumental, aunque la admite y he ahí una tensión latente y que revela algunas paradojas de la propia base social (supuestamente configurada como comunidad). En segundo lugar, relacionalmente enmarcado en una dialéctica de la representación que encuen- 
tra su expresión más nítida en otra clave modernizante: las comunidades locales son sinónimo de atraso, superstición e inmovilismo, representación que permite validar su lugar subordinado y dependiente en las relaciones con el mercado y con el Estado 4 .

Los tres casos -situados en las comunas de Calbuco, Quellón y Guaitecas- que a continuación se presentan, ocurren en el marco de las dinámicas reseñadas. Si bien las tensiones y conflictos que aquí se retratan se refieren a situaciones entre actores de las comunidades de pesca artesanal, es decir, al interior de la misma base social, lo que hay $-y$ de forma muy condicionante- es un trasfondo relacional en donde Estado y mercado son altamente relevantes en el ejercicio macro y microsocial del poder. Aun cuando su lugar decisivo, sobre todo en determinadas perspectivas locales, aparezca en un segundo plano o incluso invisibilizado. En los tres el énfasis estriba en las interfaces comunidad/ Estado y comunidad/mercado, procurando no perder la perspectiva de la complejidad, a objeto de ilustrar etnográfica y documentalmente las tensiones que allí se producen pero sobre todo las formas localizadas y/o territorializadas, de respuesta, reformulación o resistencia frente a las encrucijadas en cuestión. El primero refiere a la gestión fuera de norma de las Áreas de Manejo y Explotación de Recursos Bentónicos, en la comuna de
Calbuco. El segundo analiza la promulgación de la Ley Lafkenche en 2008 y su articulación con la Ley General de Pesca y Acuicultura, que data de 1991. Por último, en el tercer caso, se propone una retrospectiva crítica de la implementación de la Zona Contigua en el límite de las regiones de Los Lagos y Aisén.

Metodológicamente los resultados que aquí se exponen derivan de tres investigaciones etnográficas, sucesivas en el tiempo, iniciadas en 2006 en el marco de un trabajo de campo para la realización de una tesis de doctorado, el que concluyó en 2010, luego continuadas en 2011 (hasta la fecha) bajo financiación de dos proyectos Fondecyt (11110542 y 1112204) y un proyecto auspiciado por la Dirección de Investigación de la Universidad Austral de Chile (DID-UACH S-2015-46). Las principales técnicas que se utilizaron son la entrevista semiestructurada, el grupo de discusión, las redes semánticas naturales (en proceso de análisis) y el registro de notas de campo. En este sentido las limitaciones del trabajo se encuadran en el carácter cualitativo del proceso investigativo (análisis etnográfico y documental), no obstante he procurado contrastar dicha base de datos con el análisis y el procesamiento de las series estadísticas disponibles, ya sea en el ámbito de la pesca artesanal como de la acuicultura. 


\section{Mapa: Sur-austral de Chile}
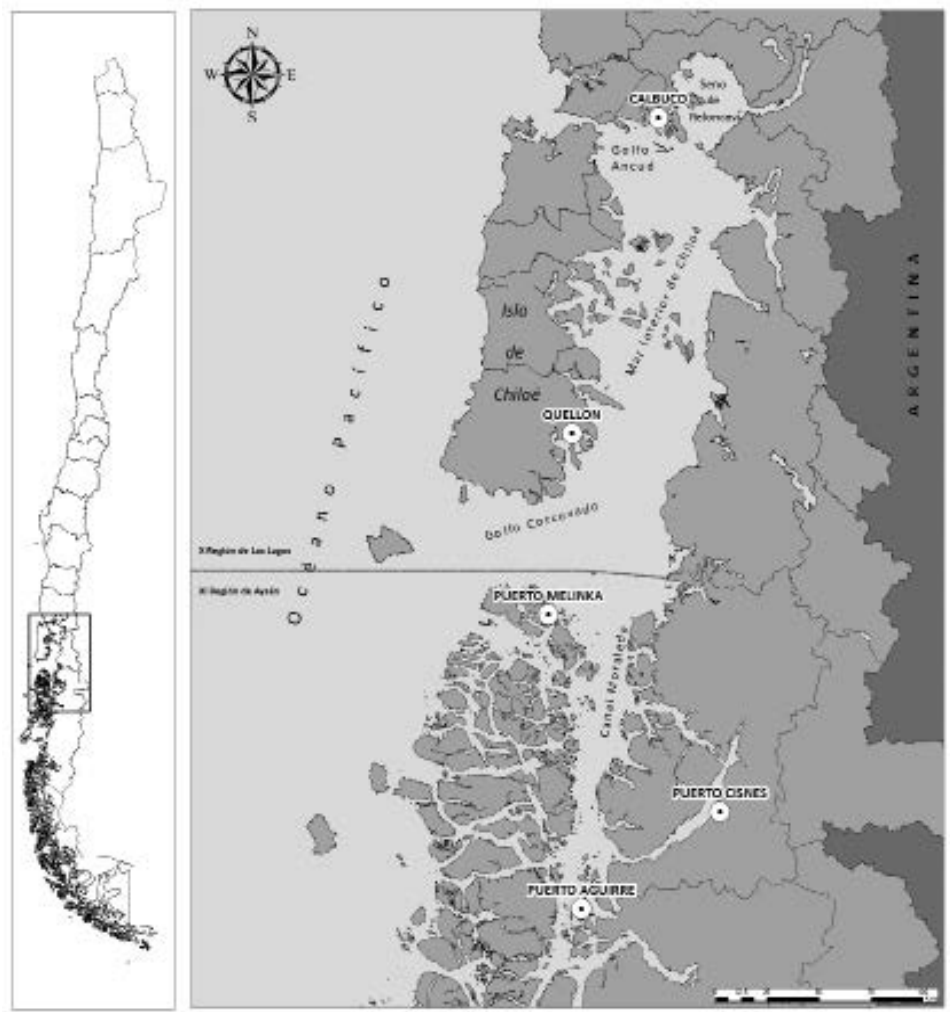

Fuente: Preparado por Zamir Bugueño

II. La gestión de las áreas de manejo en Isla Quihua, Calbuco: Un caso de resistencia creativa

Las Áreas de Manejo y Explotación de Recursos Bentónicos (AMERB), constituyen una medida de administración estandarizada que pretende subsanar, bajo modalidades de comanejo y a largo plazo, el problema de la sobrepesca y en consecuencia el agotamiento de determinadas pesquerías bentónicas (Marín \& Gelcich, 2012); en principio estuvo especialmente focalizada en el loco (Concholepas concholepas), pero luego de sucesivas apropiaciones locales termina aplicándose al manejo de otros recursos, tales como las algas o algunos bivalvos. En su definición técnica una AMERB:

\begin{abstract}
"es una zona costera geográficamente delimitada, entregada en uso, en forma exclusiva, por el Servicio Nacional de Pesca a una organización de pescadores artesanales legalmente constituida, con el fin de realizar una explotación controlada, de los recursos bentónicos presentes en el área, a través de un Plan de Manejo" (SERNAPESCA, 2005).
\end{abstract}

Los objetivos generales de las Áreas de Manejo son: a) Contribuir a la conservación de los recursos bentónicos, b) Contribuir a la sustentabilidad de la actividad económica artesanal, c) Mantener o incrementar la producti- 
vidad biológica de los recursos bentónicos, d) Incrementar el conocimiento del funcionamiento del ecosistema bentónico, generando información útil para el manejo y e) Incentivar y promover el manejo participativo coordinando esfuerzos estatales y del sector pesquero artesanal.

El caso que a continuación se presenta tiene como base la gestión de las AMERB más allá de las normativas establecidas en la Ley (LGPA), revelando, desde mi punto de vista, una capacidad colectiva latente para reformular los proyectos y las soluciones transferidas desde el ámbito experto. La experiencia tuvo lugar en Isla Quihua, comuna de Calbuco.

En un grupo de discusión, realizado en 2012, pudimos instalar una conversación con habitantes de la comunidad de San Antonio estero. Se trata de un pequeño asentamiento de alrededor de 25 familias que habitan el bordemar y dedican su tiempo de trabajo a la producción de hortalizas, a la ganadería a pequeña escala y a la pesca artesanal -principalmente bentónica. A estas actividades de base tradicional debe añadirse el empleo estacional o temporal en las industrias conserveras, de larga data en la comuna de Calbuco, y más recientemente en la industria salmonera, ya sea en las plantas maquiladoras y en los propios centros de cultivo. Podría decirse que se trata de una economía típicamente bordemarina, agrocostera, pero con una fuerte identidad asociada a la pesca artesanal. Esto último -recurrente en todo el mar interior de Chiloé y Aisén- lo hemos constatado a través de una serie de observaciones etnográficas, basadas en técnicas mixtas levantamiento y análisis de datos (notas de campo, grupos de discusión, entrevistas a actores clave), en donde se advierte que el sentido de la vida económica local se articula en la pesca artesanal. Como puede advertirse en las siguientes referencias esta no se limita a una relación instrumental, ya sea con el territorio o con las propias comunidades del lugar.

\footnotetext{
"Somos una forma de vida y... nos [imponen] una ley que nos restringe y que, [por ejemplo] nos dice "tú dedícate a esto [y a nada] más". Entonces, más encima, [todo eso] después del sacrificio que significa ser pescador, te restringen y te dicen que "no puedes pescar más que pulpo porque [solo ese recurso] te vamos a dar... [Cuando yo] pienso en el buzo mariscador y en su sacrificio, [tal como] dicen mis compañeros, llego a la conclusión de que la pesca artesanal es vida"5.
}

De mismo modo, el futuro en tanto proyecto imaginado y deseado se concibe como un escenario de prosperidad en donde todas las actividades tradicionales del bordemar tienen cabida pero estructuradas u organizadas a partir de la pesca artesanal. Es cierto que se reconoce la adversidad que supone la articulación entre comunidad, empresas y Estado, no obstante, más allá de las evidentes disrupciones -por ejemplo, consecuencias destructivas de las prácticas industriales- la gente percibe que en sus propias capacidades de seguir siendo lo que se es (como cultura económica) estriba la potencialidad de una forma vida local que persiste en sus virtudes.

Sostuvimos, en el análisis de los resultados de la citada investigación, que los escenarios de prosperidad, bajo la nomenclatura futuros imaginados, implicaban una proyección deseada pero fundada en un contexto real más que ideal. En ese marco, se trata de escenarios que redefinen el lugar de los elementos y componentes que ya constituyen aquellos contextos. De tal manera que vectores tan exógenos como la industria de más reciente localización (la salmonicultura) están incluidas en estas proyecciones. Lo mismo puede decirse de los dispositivos de gestión 
del desarrollo, transferidos desde las agencias públicas, como es el caso de la AMERB o de algunas modalidades de microemprendimiento. Sin embargo, siguiendo las tesis que advierten sobre la capacidad hibridacional de las economías locales-tradicionales (Gudeman \& Rivera, 1990; García Canclini, 1990; Escobar, 2008) en contextos de modernización y dinámicas de globalización, interesa aquí mostrar cómo este tipo de fórmulas que, en principio son exógenas, terminan siendo reinventadas desde las lógicas prácticas del lugar. Brevemente entonces reseñaremos el caso de las AMERB en Isla Quihua.

Hace unos tres o cuatro años por iniciativa propia, es decir, sin intervención de expertos técnicos, cuatros sindicatos del sector de Isla Quihua deciden utilizar sus AMERB con fines de conservación pero bajo una modalidad que no está contemplada en la Ley. La experiencia consistió en "cerrar cuatro sectores", incluyendo las AMERB de los sindicatos en cuestión, con el propósito de recuperar bancos naturales. El cierre colectivo se mantuvo durante seis meses, los resultados fueron positivos para los sindicatos; pues, como nos lo relata uno de los socios que lideró el proceso los bancos naturales evidentemente se recuperaron.

"Lo que hacemos acá es dejar días sin trabajar, lugares por un tiempo, dependiendo a veces también del factor climático. Porque el factor climático a veces favorece el mantener los recursos. Por ejemplo cuando hay días de mal tiempo y no podemos salir a trabajar, y el recurso en el mar abunda más. Esa es una, y la otra es cuando tiempo atrás nosotros estuvimos cuidando un sector ahí entre cuatro sindicatos por seis meses en que no entramos a la mar. No entramos a extraer recursos, y el recurso abundó casi en un cien por ciento"6.

Se trata de una experiencia particular pero que nos permite advertir dos cuestiones centrales. En primer lugar, que las AMERB ocurren más allá de sus diseños formales de comanejo. Son estructuras que acontecen, es decir, se recrean y reformulan constantemente en su devenir social (Sahlins, 1988). En segundo lugar, que las AMERB, más allá de sus aspectos críticos revelan un uso de recuperación territorial deliberado por parte de las organizaciones de pescadores. Podríamos añadir, como tercera cuestión destacable, que las respuestas locales admiten resultados diversos -e inesperados- a partir de la heterogeneidad organizacional, factor decisivo en el potencial de éxito de las AMERB (Gelcich, Edward-Jones, Kaiser \& Watson, 2005).

Me parece interesante reseñar aquí el testimonio conversacional de un dirigente de la Federación bentónica de Calbuco. La conversación tuvo lugar en enero de 2016, durante nuestro último trabajo de campo en isla Quihua. Recordando la experiencia y la perspectiva que hace ya tres años nos había entregado Juan Carlos C., le pregunto cómo ha sido para ellos, como sindicato, el disponer de un área de manejo. Su respuesta solo me sorprende en parte:

Desde el punto de vista de ganancias es nulo, cero... con las áreas de manejo no hemos ganado ni un peso. Las únicas que todavía dan algo son las que tienen loco, pero para nosotros nada, no es rentable (cita reconstruida etnográficamente).

Le pregunto entonces para qué solicitar algo que no rentabiliza y su respuesta es sugerente:

Las áreas de manejo nos sirven para la cuestión de los proyectos, para obtener ese tipo de recursos, además para impedir que se nos metan las empresas, las salmoneras (cita reconstruida etnográficamente).

Efectivamente, se trata de eso. Las AMERB comportan además un proyecto político que tampoco fue contemplado en su diseño técnico, 
pues como se explica en la cita permiten la articulación comunidad de pescadores-Estado con el propósito de asegurar cierto flujo de recursos. Pero la cuestión territorial también es relevante en ese mismo sentido. Una impresión similar tenía en 2010 un respetado biólogo marino de Fundación Chinquihue en Puerto Montt y, probablemente, una de las personas con mayor autoridad para hablar sobre este tema en Los Lagos: Los sindicatos piden AMERB como forma de defender su territorio de las empresas, en particular de las salmoneras.

Quisiera citar la impresión de Claudia Torrijos -ex coordinadora regional de Fondo de Fomento de la Pesca Artesanal-, quien además de refrendar este punto de vista, reflexiona sobre un aspecto aun más estructural y determinante. En pocas palabras, Torrijos cree que para las comunidades de pescadores las AMERB han implicado, en el marco de una política generalizada de organización ("regulación") de las pesquerías, una creciente sedentarización y ruptura de los itinerarios extractivos, localizando a las flotas en espacios particulares, al menos como propósito formal-administrativo7. Por sobre el éxito y por sobre el fracaso de una modalidad estratégica de comanejo, las AMERB contribuyen a socavar la dinámica de movimiento y translocalización histórica de los sistemas de pesca artesanal. Bajo eso punto de vista son, sin lugar a dudas, un dispositivo modernizante. Sin embargo, es evidente que esto solo puede constituir una afirmación parcial y relativa.

Lo que quiero rescatar con el caso de isla Quihua, en los testimonios de ambos pescadores, es la resistencia, la capacidad hibridacional transgresora y creativa, de la base social local -del lugar, en el sentido escobariano- para reformular ese dispositivo de modernización. En un caso, llevando su expresión territorial hacia una matriz colectiva trans-sindical, con un fin deliberado de conservación del fondo marino; y en el otro caso, utilizando su diseño jurídico-institucional para aprovechar los aportes de la agencia pública.

No obstante, esto no siempre es así y los procesos suelen decantar en escenarios más pesimistas y monocordes. El proyecto modernizante tiene enorme fuerza de disrupción. Veamos un segundo caso. Ciertamente, las impresiones del dirigente de Calbuco respecto del influjo divisorio que tienen las políticas públicas para la pesca artesanal nos serán relevantes para estructurar el siguiente relato.

\section{Fotografía 1: San Antonio estero, Isla Quihua, Calbuco}

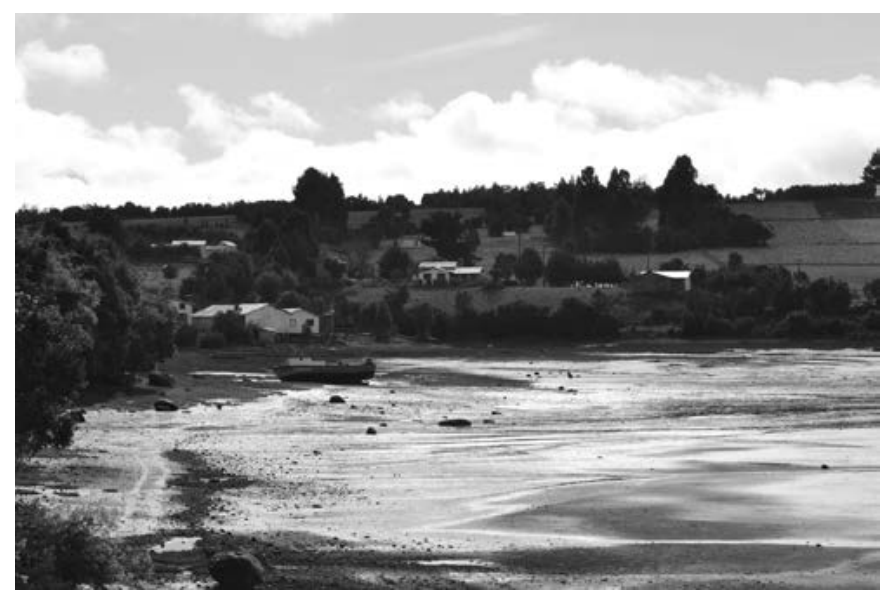

Fuente: Autor 


\section{La superposición imaginaria y material de las AMERB y de los Espacios Costeros Mari- nos para Pueblo Originarios en la barra de Chaiguao, Quellón}

La inclusión en la legislación actual de un nuevo dispositivo de administración y manejo de recursos marino-costeros ha sido controversial. Los Espacios Costeros Marinos para Pueblos Originarios (ECMPO), Ley 20.249 (31/01/2008) surgen en el marco de una dinámica de visibilización de la problemática territorial. Hasta ese entonces ni la LGPA ni ningún otro cuerpo legal reconocía el uso consuetudinario del borde costero y del espacio marino en general (Zelada \& Park 2013), lo que sumado a la presión por parte de determinados grupos de activistas indígenas y/o proindígenas -para obtener dicho reconocimiento- favoreció su promulgación.

Finalmente el proceso legislativo se concreta y bajo una modalidad basada en la inclusión, al menos jurídica, se decretan las primeras ECMPO. La inclusión implica que el establecimiento de una ECMPO no puede ocurrir sobre usos ya establecidos, y en particular destacamos su relación social con las $A M E R B$, dado que se trata de usuarios de similar condición e incluso características, esto porque muchas organizaciones de pescadores artesanales han estado y están conformadas por personas de origen indígena, en particular mapuche-huilliche desde la región de la Araucanía al sur.

“(...) la Subsecretaría verificará, en el plazo de dos meses, si se sobrepone a concesiones de acuicultura, marítimas o áreas de manejo otorgadas a titulares distintos del solicitante. En caso de constatarse una sobreposición con concesiones de acuicultura, marítimas o áreas de manejo otorgadas que impidan absolutamente el otorgamiento del espacio costero marino de pueblos originarios, se comunicará esta circunstancia al solicitante, mediante una resolución denegatoria. En caso de que la sobreposición sea parcial, la Subsecretaría propondrá al solicitante una modificación del espacio costero marino de pueblos originarios" (Título II, art. 7).

Nuestra primera impresión etnográfica, de contacto cara a cara con personas o pescadores implicados en la solicitud de ECMPO, tuvo lugar en la comuna de Guaitecas, región de Aisén, en 2012 y 2013, por entonces nos encontrábamos realizando un registro de campo para investigar la relación entre pesca artesanal y salmonicultura. En este contexto pudimos entrevistar y conversar con varios dirigentes de la pesca artesanal del lugar, uno de ellos era quien estaba (y está) a la cabeza de la solicitud de un ECMPO en la isla Leucayec, al sur del archipiélago. Aquella solicitud-actualmente en proceso- se ha sostenido sobre la base de una comunidad indígena formada hace no más de 10 años, organización que también es liderada por el dirigente en cuestión.

Por entonces, en nuestras dos últimas visitas de campo (marzo 2013 y febrero 2014), no dejó de sorprendernos que a la tensión patente entre organizaciones de pescadores y centros de engorde de salmones, se añadía una tensión que en principio nos resultó inesperada y que podría definirse como una reticencia y distancia crítica de algunos dirigentes de pescadores, también de la comuna, hacia la solicitud por parte de la organización indígena de la ECMPO de isla Leucayec. En el trasfondo de este desajuste local constatamos un problema territorial muy similar al suscitado progresivamente con las empresas del rubro acuícola, referido al temor declarado de los pescadores a perder control sobre áreas que históricamente han apropiado para la extracción de recursos bentónicos y, en cierta medida, madereros. En este sentido, la ECMPO se nos revelaba paradójica- 
mente como una figura territorialmente amenazante. Por supuesto, todo esto, en la percepción de algunos pescadores del lugar.

El desencuentro dirigencial que observamos en Melinka, principal poblado de la comuna de Guiatecas, nos serviría como referente para problematizar otra situación similar, suscitada en la barra de Chaiguao, en el extremo sur de Quellón. A mi modo de ver las evidencias hacen de este un caso paradigmático $\mathrm{y}$, hasta cierto punto, inquietante. Como pudimos advertir en nuestras conversaciones etnográficas "la barra" es y ha sido por décadas una excepcional y muy productiva pradera de luga negra, tal vez una de las más prolíficas en todo el mar interior de Chiloé (Navarro, 2014). Ya en los años ochenta el lugar era trabajado por familias provenientes de diversas zonas de Chiloé y especialmente de la comuna de Quellón. Sin embargo, producto de las dinámicas de formalización y modernización impulsadas con la promulgación de la LGPA termina constituyéndose allí un sindicato de pescadores artesanales y posteriormente un área de manejo (decreto 1207, Subsecretaría de Pesca). El recurso, que hasta ese entonces era de uso común -"common-pool-resources", en la expresión acuñada por Elinor Ostrom (1990)- pasaba a quedar limitado, en su extracción, bajo una figura de comanejo contemplada en la legislación.

De acuerdo a los testimonios que pudimos obtener, inicialmente el Sindicato tuvo un carácter unitario, amplio e inclusivo, pero en el curso del tiempo, como ha sido frecuente en otras circunstancias similares, surgieron desavenencias -vinculadas a la administración de la AMERB- y la asamblea de socios decide expulsar de la organización a quienes, según sus registros internos, habían incumplido o fallado sus compromisos. La consecuencia inmediata de ese hecho fue la pérdida de sus derechos de explotación de luga negra, en el área de manejo, para una veintena de socios y socias de la organización. Como era de esperarse estas personas persistieron en el uso extractivo de la pradera -pues se trata de una de sus principales de fuentes se sustento-, aumentando la tensión con el sindicato.

Pues bien, luego de un tiempo, los socios y socias expulsados comienzan las gestiones -asesoradas por especialistas- para solicitar en la misma barra de Chaiguao un Espacio Costero Marino para Pueblos Originarios. La solicitud era plausible pues estas personas eran de origen mapuche-huilliche y además estaban en condiciones de demostrar que durante décadas habían venido practicando un uso tradicional y ancestral sobre el territorio en cuestión. Se activa entonces, por un lado, un proceso de tramitación jurídica del ECMPO -previa constitución de una comunidad indígena- $y$, por otro lado, se activa un proceso de reivindicación étnico-cultural que trasciende esa dimensión instrumental y que, a nuestro juicio, terminaría radicalizando aun más las tensiones en el lugar. La siguiente imagen es etnográfica y retrata de forma muy patente lo antes dicho.

Luego de cuatro visitas a la barra de Chaiguao, ocurridas entre 2012 y 2014, habíamos aceptado participar en una reunión ampliada entre comunidad indígena y sindicato. Por separado habíamos acordado los términos de ese encuentro con la presidenta de la comunidad y con la presidenta del sindicato. Accedimos porque nos lo solicitaron al advertir que nuestro equipo de investigación no solo incluía a dos antropólogos, sino también a una bióloga marina con vasta trayectoria en programas de 
repoblamiento de algas, y quien coincidentemente ya había trabajando en un proyecto para la barra de Chaiguao.

Todo estaba preparado. Nos reuniríamos en el quincho que la comunidad indígena había construido hace poco, aprovechando recursos estatales para impulsar en el lugar un proyecto de turismo étnico. Nosotros ayudaríamos para la realización de un asado con la idea de contribuir a un clima de diálogo entre ambas partes, que en rigor seguían siendo una misma comunidad de recolectores de luga negra. La barra de Chaiguao tiene una extensión de unos cuatro kilómetros de costa logitudinal, desembocando hacia el sur oeste. Desde esta posición es posible observar el golfo de Corcovado, apreciable en toda su imponente magnitud. La vista se pierde en el mar, es el extremo suroeste de Chiloé.

Ya en el inicio de la reunión, a la que asistieron unas 40 o 50 personas, pudimos advertir que las tensiones eran latentes. La presidenta de la comunidad indígena, la señora María, nos pidió que introdujésemos las ideas principales del encuentro. Se suponía que era una actividad que permitiría conocernos y aprovechar de crear un espacio para el diálogo entre personas que, según constatamos antes, estaban bastante distanciadas. Pero lo que nunca imaginamos -tal vez muy ingenuamente- era que el nivel de tensión ya había derivado en un conflicto manifiesto. Mientras yo mismo reseñaba los propósitos de nuestro proyecto (relación entre pesca artesanal y salmonicultura), comentando que la barra de Chaiguao, al igual que otras latitudes del sur-austral, era el escenario de la expansión de la salmonicultura, y luego proseguía apuntando hacia la actividad artesanal-tradicional del lugar, fui abruptamente interrumpido por una dirigente del sindicato quien nos interpeló para preguntarnos:

¿con quién están ustedes?, ¿con quién quieren trabajar?, ¿con el sindicato o con esta señora? [refiriendo en tono severo a la presidenta de la comunidad indígena], porque si van a trabajar con ellos nosotros nos retiramos inmediatamente de esta reunión (cita reconstruida etnográficamente).

En ese momento casi la mitad de las personas asistentes se salen del quincho, algunas visiblemente molestas, para luego reunirse en una especie de placita ubicada algunos metros más allá detrás de un pequeño galpón de acopio.

Mientras las personas de la comunidad indígena nos señalaban que esto es "siempre así" y que "esa mujer es de fuera", unos minutos más tarde las mismas personas del sindicato nos vienen a buscar para explicarnos lo sucedido. Accedemos y vamos a escuchar las razones del sindicato - la presidenta había faltado a la cita-, quienes nos dicen que ya no toleran a la comunidad indígena puesto que "están tratando que quitarnos nuestro lugar de trabajo", apropiarse de todo el sector incluyendo el área de manejo. En ambos grupos percibimos varias sensaciones en el ambiente, tal vez resumibles en rabia y temor hacia los otros, hacia personas que desde hace mucho tiempo son parte de la misma comunidad o del mismo espacio social.

De pronto, mientras estamos reunidos con el sindicato, comienza a llover, entonces ocurre algo que nos resulta significativo. Todas las personas, sin distinción organizacional, se dispersan por la pradera y comienzan a proteger sus acopios familiares de luga. Esta imagen nos revela que, mientras tiene lugar una tensión -y a estas alturas un conflicto desatado- por los derechos formales de uso del lugar, sigue prevaleciendo en parte una lógica práctica y territorial basada 
en la costumbre. Advertimos que la gente sigue trabajando la pradera, y en la práctica respetando el uso colectivo. De hecho, más tarde, verificaríamos esta impresión, sin embargo tampoco podíamos soslayar que el conflicto era cada vez más patente $y$, en cierto modo, amenazante para el conjunto de la comunidad (indígena y sindical).

Luego de esta experiencia hemos mantenido el contacto con personas vinculadas a la extracción de luga en la barra de Chaiguao, quienes nos han dicho que la situación se mantiene en más o menos en los mismos términos. Hasta ahora la ECMPO no ha prosperado pero su tramitación continúa.

Una de las cosas que más llamó nuestra la atención durante esas cuatro visitas a Chaiguao, fue cierta invisibilidad, por parte de los involucrados, de otros actores presentes en el territorio y que probablemente son aun más decisivos y condicionantes de su gestión de los comunes. En particular me refiero a las empresas salmoneras, con jaulas desplegadas en la costa, a los intermediarios que controlan -como sucede en todo el sur-austral- el comercio de la luga y de otras pesquerías, y, por supuesto, al propio Estado que, a través de la transferencia de diseños administrativos complejos, incide directamente en este tipo de fracturas sociales. En cambio, las relaciones de poder, con los niveles de tensión descritos más arriba, solo parecen ser patentes y conscientes entre actores de idéntica condición sociocultural. En ese marco tampoco advertimos que aquella tensión derive en interpelaciones a esos otros actores que también se apropian territorialmente del borde costero, y de forma que podríamos calificar de destructiva y fragmentaria, para usar el concepto sugerido por Hinkelammert (2001).

Reseñemos entonces las impresiones que nos compartiera el mismo dirigente, citado antes, a propósito de la relación AMERB y ECMPO en la comuna de Calbuco y en la zona de Chiloé. Es enero de 2016 y él acaba de llegar de Puerto Montt, en donde sostuvo -junto a otros dirigentes- una reunión con las autoridades del sector pesquero, entre ellos con funcionarios de la Subsecretaría de Pesca. Le pregunto su opinión sobre los ECMPO y sobre las relaciones entre los sindicatos y las comunidades indígenas. Me comenta que en la reunión de esa mañana un directivo sectorial les recomendaba cuidar sus espacios, defenderlos: "tienen que defenderse, no pueden permitir que las comunidades indígenas les ocupen los espacios". Pero, desde su punto de vista, el problema no pasa por los intereses de las comunidades indígenas, que ciertamente están entrelazadas con los sindicatos, de hecho él y varios socios pertenecen también a comunidades indígenas; el problema es, por un lado, la división intencionada que, según el dirigente, se ha impulsado desde las agencias estatales con el fin de "crear conflictos entre nosotros mismos". Y, por otro lado, en particular sobre el caso ECMPO, por la presión internacional que tiene el Estado chileno de cumplir sus compromisos internacionales para con los pueblos indígenas (por ejemplo, Convenio 169 de la OIT). Aun así, fuera de la supuesta presión internacional, para don Simón se trata de conflictos pensados por la administración estatal con el fin de distraer a los pescadores de la cuestiones que realmente importan, es más, sostiene que las diferencias entre sindicatos (por AMERB) y comunidades indígenas (por ECMPO) solo se podrán solucionar construyendo acuerdos entre los propios actores en disputa. Sin embargo, tampoco deja de subrayar que no será fácil lograrlo producto de las intervenciones del Estado. 
Fotografía: Área de manejo, barra de Chaiguao, Quellón.

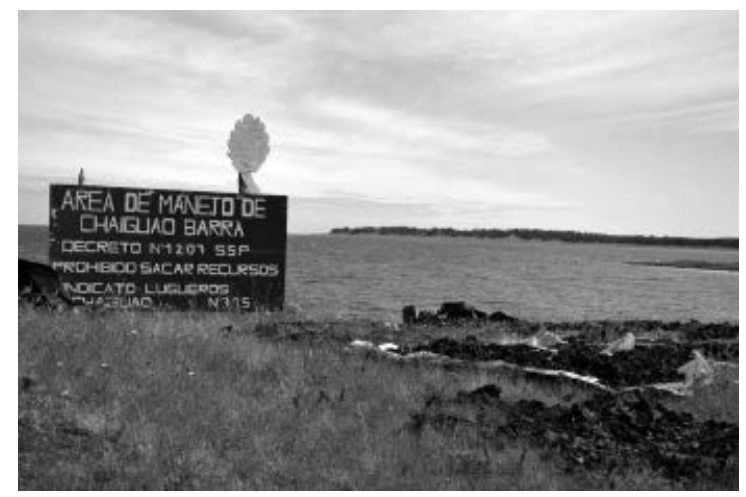

Fuente: Autor

IV. La zona contigua entre Aisén y Chiloé: Un largo escenario de tensiones entre pescadores artesanales

La reseña etnográfica que me permite ilustrar este tercer caso, está basada en registros de campo realizados en Aisén y Chiloé entre los años 2003 y 2007 . No obstante lo anterior, en los últimos años -entre 2012 y 2014- pudimos refrendar las perspectivas y las dinámicas sociopolíticas que aquí se presentan, esto en el marco de las investigaciones que fundamentan los dos casos anteriores.

En efecto, la constatación documental y etnográfica de las tensiones entre pescadores artesanales de regiones contiguas, cobra especial relevancia en el límite marítimo que separa administrativamente Los Lagos y Aisén. En particular las encrucijadas más complejas se han suscitado desde hace casi dos décadas en el entorno de las islas Guaitecas, el cual también es reclamado por pescadores artesanales de Los Lagos. Mi interpretación en este caso, ha sido construida a partir del levantamiento de información en diálogo con actores de tres espacios del campo-borde costero:
Quellón, Guaitecas y Puerto Aisén. Cada uno de ellos representa un polo clave en este escenario político-cultural.

Básicamente puedo definir una tensión constitutiva. Parte importante de la flota bentónica de la región de Los Lagos, en especial del sur de Chiloé (Quellón, en particular), reclama derechos históricos sobre los bancos naturales de la región de Aisén ${ }^{8}$. Es una tensión generalizada, digamos entre regiones pesqueras, porque efectivamente hay nexos constatables entre una y otra en materia de pesca artesanal. Entre las más significativas destacaría las relaciones de parentesco, las relaciones comerciales, las relaciones político-administrativas ${ }^{9}$, y por supuesto las relaciones histórico-culturales.

La primera gran crisis por la explotación en régimen de zona contigua para el recurso erizo, se suscita en $2001^{10}$. Ese año las movilizaciones -localizadas en Guaitecas y Quellón- derivaron en una restricción generalizada al ingreso de buzos mariscadores de la isla de Chiloé a las costas aiseninas. Esta situación incrementó aun más las tensiones entre unos y otros pescadores, favoreciendo un clima de inestabilidad en 
ese límite regional. Es claro que esa crisis tuvo como trasfondo el patente agotamiento de los bancos naturales, algo que entre otras razones debe explicarse por la desregulación selectiva del mercado y consecuentemente por los irrisorios precios de comercialización en la primera fase, es decir en el trato buzo/intermediario. En ese contexto la crisis de los bancos naturales era cuestión de tiempo. Por supuesto que también habría que tener en cuenta factores endógenos, tales como las prácticas extractivas intensivas de las flotas bentónicas y la tendencia a conformarse con un recurso comercializado sin valor agregado.

Los años 2004 y 2005 fueron intensos en cuanto a movilizaciones. En septiembre de 2004, en un contexto de protestas callejeras en Puerto Aisén y Puerto Chacabuco, la pesca demersal reclamaba -como otras veces- una redistribución de las cuotas de captura. Hasta ese entonces las comunidades bentónicas solo participaban en el movimiento de forma solidaria y pasiva, por ejemplo suscribiendo las declaraciones de sus colegas de la pesca de merluza. No obstante, en febrero de 2005 el conflicto se agudiza, ampliando su trasfondo a la cuestión bentónica, pues algunos sindicatos de Los Lagos (en especial de Quellón) solicitan a la Subsecretaría de Pesca una nueva autorización para capturar erizos en las costas de Aisén. La situación no era para nada sencilla, pues en la región de Los Lagos hay en la actualidad sobre seis mil buzos inscritos, mientras en Aisén no llegan a los mil (SERNAPESCA, 2014). Por supuesto que la principal argumentación de esta reconsideración normativa era el derecho histórico de los pescadores de Chiloé en aguas australes, algo que ciertamente es indiscutible. En efecto, la escasez de recursos en las costas de Los Lagos es tal que casi toda la flota bentónica de Chiloé -e incluso de zonas como Calbuco o Carelmapudepende en gran medida de los bancos naturales ubicados en los canales aiseninos.

Luego de un conflicto que tuvo episodios alarmantes, entre las comunidades implicadas, se logró a fines de 2005 un acuerdo -al parecer más definitivo- de uso contiguo de las costas localizadas en la parte noroeste del litoral aisenino (comunas de Cisnes y Guaitecas). Sin embargo, este es un acuerdo al que llegaron los gobiernos regionales de Los Lagos y Aisén, con la aprobación de los sindicatos de Quellón (región de Los Lagos) y Guaitecas (región de Aisén), y que consecuentemente generó inquietud en el resto de los pescadores artesanales de la región de Aisén, en particular en los sindicatos bentónicos (léase en Islas Huichas y en Puerto Aisén).

\begin{abstract}
"Mediante un decreto emanado desde el Ministerio de Hacienda, se estableció la transferencia para este año, de un total de 101 millones 500 mil pesos para proyectos e iniciativas de los pescadores artesanales de Las Guaitecas, que beneficia a cuatro sindicatos de Melinka y Repollal y la Federación de Pescadores Artesanales de Guaitecas"11.
\end{abstract}

A modo de síntesis este conflicto negociado (dialogado) y contractual, expresa un componente de asimetría que se da en un escenario político del campo. Si bien las organizaciones bentónicas de Guaitecas negocian con sus pares de Chiloé (Quellón), detrás de esas organizaciones hay entidades e instituciones que desequilibran la paridad. Estamos hablando del Gobierno Regional de Los Lagos, que debe procurar que en cualquier negociación de zona contigua con Aisén, se resguarden las fuentes laborales de una flota de pescadores cuyas costas han llegado a niveles límite de saturación y escasez de recursos. Este escaso peso institucional de 
la base sindical, coyunturalmente organizada, revela su propia condición (de debilidad) en el marco de un escenario que incide de manera importante en su vida económica.

\section{Una segunda vertiente de este conflicto ocurre} entre pescadores artesanales de la misma región. En rigor, sucede que desde la suscripción del acuerdo en ese entonces, los dirigentes de la comuna de Guaitecas son acusados por otros dirigentes regionales de "vender el litoral", de "no saber donde están parados" o de "traición" hacia sus compañeros. En nuestro trabajo de campo, realizado en mayo y junio de 2007, constatamos esta situación. Valga para ello el siguiente registro etnográfico:

Su mensaje es que al Gobierno no le interesan los [pescadores] artesanales, más encima tiene todo el problema de las zonas contiguas con la gente de Quellón. A propósito de eso le preguntamos qué tal le parece el acuerdo de zona contigua al que llegó Melinka con Quellón. Nos cuenta que el es melinkano, que lleva como 15 años en Puerto Aisén pero que su gente no sabe donde está parada. La verdad es que más nos sorprende, pues se refiere en términos durísimos a los dirigentes de Melinka. A mí me queda dando vueltas si acaso esto será una ruptura grave en el conjunto de las organizaciones regionales. Por su tono lo parece... que los melinkanos nos vendieron, que es pan para hoy y hambre para mañana, en $\mathrm{fin}^{12}$.

No sobra decir que la pregunta formulada a Ruiz se hizo explícita en la totalidad de entrevistas realizadas en 2007. Al respecto pudimos constatar que existía en ese entonces una percepción generalizada (entre pescadores artesanales, y personas de las comunidades), en orden considerar ese acuerdo como una seria amenaza al patrimonio económico-productivo, es decir al capital natural, de las costas de Aisén. Puntualmente en cuanto a los bancos naturales de erizos:
"[Los dirigentes de Guaitecas] no le tomaron el peso a lo que estaban haciendo porque, dejarle la puerta abierta, es como decirles "oye, entren a mi casa, bárranla y después váyanse". Porque ellos no dejan nada en la región, nada. O sea, ¿de qué le sirvió a Melinka? De nada porque yo creo que ellos no ganan nada. No ganan progreso ni mejores precios, nada. Todo lo contrario, se mantiene el precio de los productos. Porque a Puerto Montt no le está faltando productos. Puerto Montt no está diciendo: sabes que no tengo erizos, voy a tener que pagar más para que me traigan, si no que vayan a buscar no más si la [Aisén] tiene. ¡Y teníamos en abundancia! No sé ahora cómo estarán los bancos naturales, pero antiguamente había, había en gran cantidad"13.

Una visión más distante y en parte objetiva, es la que nos reporta un dirigente demersal de Puerto Chacabuco:

\footnotetext{
"Melinka muchas veces se ha aislado, incluso ahora estamos más cercanos, pero muchas veces se ha aislado y ha tomado decisiones que yo pienso que a ellos a futuro les va a afectar, incluso que directamente afectaron a Puerto Aguirre... Porque dentro de la zona, están incluidas zonas que ocupa la gente de Aguirre para sacar erizos o sacar otros tipo de productos, que es más o menos dentro de su área"14.
}

La tensión interna supone varios matices en las relaciones entre pescadores adscritos a una misma administración territorial (región). Pensemos por ejemplo en conflictos declarados, en desarrollo y, en alguna medida, inciertos, o bien pensemos en diálogos conflictivos, por citar algunos. De cualquier modo se trata de un equilibrio bastante provisorio y precario, pues las relaciones y sus valoraciones son coyunturales. Hay cooperación, hay diálogo y hay conflicto, quizá todo al mismo tiempo, pues no son univalentes. Simultáneamente tienen lugar todas las posibilidades, se expresan unas y otras. Esta no es una configuración mecánica, por ello habrá que observar cómo estas rela- 
ciones devienen dinámicas y coyunturales. En el concepto de Sahlins (1988), están inmersas en el tiempo caliente y son cambiantes; aunque por supuesto se tienda hacia cierta estabilidad y persistencia ${ }^{15}$.

Sin embargo, aquí cabe plantear alguna distinción. El lazo cultural que conecta el sur de Chiloé con las Guaitecas, las Huichas y en parte con Puerto Aisén, impone otra condición a esta situación. Entonces no se puede hablar de una ruptura, tal como lo confirma un dirigente bentónico de Puerto Aisén: Nosotros seguimos y vamos a seguir trabajando con los cabros de Melinka, se equivocaron pero todos estamos en lo mismo. Ellos siguen viniendo a [Puerto] Aisén (cita reconstruida etnográficamente).

Entonces habría que entender que por más que esa relación se tense no es previsible una fractura definitiva, ello por un vínculo cultural-práctico estrecho, histórico y constitutivo de identidad. En efecto, al observar este mismo escenario siete años después (en 2014), pudimos advertir que las tensiones y los conflictos que en esos años habían estado patentes, ahora daban lugar a una dinámica relacional en donde la presencia constante de pescadores del sur de Chiloé en el norte de Aisén había sido internalizada y asumida no solo como un hecho formalmente institucionalizado con un acuerdo de subsidio de por medio- sino además bajo una trama discursiva que reconoce los itinerarios históricos de los chilotes -quelloninos y calbucanos, espacialmente- por todo el litoral aisenino.

\section{Conclusiones}

En los tres casos aquí analizados se advierten similitudes que merece la pena destacar.
En primer lugar, la evidencia de tensiones que, en determinadas situaciones, han derivado en conflictos. En todos es coincidente la expresión interna de dichas tensiones y conflictos, es decir, al interior de la propia comunidad pesquero-artesanal. Esto es explícito en los casos dos y tres, pero no lo es en el primero. Lo que observamos en el ejemplo de isla Quihua es una respuesta de cohesión social deliberada, a partir del desborde de las dinámicas de AMERB, frente a una presión sobre un ecosistema compartido que bajo otros arreglos institucionales locales pudo desencadenar un conflicto de intereses disímiles.

Por su parte, los casos de Chaiguao y de zona contigua Chiloé-Aisén, dan cuenta de unas respuestas inversas: el conflicto, derivado de una presión político-administrativa formal -transferida desde la agencia pública- que toma la forma explícita de una o de sucesivas confrontaciones. En este tipo de escenarios tienen lugar procesos de disolución de la comunidad -en cualquiera de sus formas-, dando lugar y expresión a una lógica de competencia por recursos escasos. Por cierto, no porque sustantivamente lo sean; sino porque en la matriz neoliberal no cabe otra concepción de la economía. De tal manera que, en ambos casos, además de la disolución de la comunidad, somos testigos de su desempoderamiento político y cultural. Político porque se socava la capacidad colectiva de construir y reconstruir el orden social -recordando la tesis de Lechner sobre la política (2006). Cultural porque ese socavamiento implica el abandono -al menos parcial- de los valores culturales propios (del lugar), los que han sido progresivamente reemplazados -en su preponderancia- por los valores modernizantes transferidos desde el consorcio Estado/mercado ${ }^{16}$. 
En segundo lugar, los tres escenarios revelan algo que paradojalmente no es del todo visible al interior del espacio pesquero artesanal. Esto es, la fuerte incidencia que en estas configuraciones conflictivas tiene el Estado y el mercado. Tal vez es nuevamente el ejemplo de Calbuco en donde podamos advertir matices y desarrollos analíticos localizados, es decir, de los actores del lugar, en orden a visualizar esos factores aparentemente ajenos e instalar procesos autorreflexivos capaces de construir escenarios de resistencia creativa frente a los influjos modernizantes más disolutivos de los valores simbólico-prácticos de los espacios bordemarinos de pesca artesanal.

No deja de ser interesante, siguiendo la tesis de Godelier (1990), cómo la superposición imaginaria de los territorios -o mejor dicho sus apropiaciones locales- deriva en tensiones que crean materialidad, reconfigurando los entramados ideacionales que precisamente condicio- nan las vidas económicas y sociales del lugar. Estos fantasmas institucionales y administrativos no solo deambulan errantes por la barra de Chaiguao o en las inmediaciones del golfo de Corcovado o del canal Moraleda -en la zona contigua- sino en todo el territorio sur-austral y en lo que parafraseando a Bourdieu (2003), podríamos llamar el campo o subcampo del desarrollo pesquero-artesanal en Chile.

Destaco entonces que no solo las similitudes nos permiten problematizar los casos reseñados, también sus diferencias. $Y$ es justamente en ellas, en sus diversas manifestaciones, en donde podemos encontrar las respuestas política y culturalmente más transgresoras pero institucionalmente más creativas, capaces de reformular el monocorde sonido y el monocromático sentido de la fantasmagórica, pero no todo poderosa, modernización neoliberal que se expande por las costas del mar interior del sur de Chile. - 


\section{Notas}

${ }^{1}$ De acuerdo a Mansilla \& Rojas (2007) el concepto habría sido propuesto inicialmente en el "Taller Puertazul" en Castro, Chiloé, para referir a la apropiación cultural en el intermareal, característica de todo el archipiélago.

${ }^{2} \mathrm{Si}$ consideramos los desembarques de especies bentónicas, incluyendo algas, para el quinquenio 2010-2014 la región de Los Lagos registró el $21 \%$ de los desembarques a nivel nacional. En cuanto a desembarques de acuicultura, considerando todas las especies, para el mismo quinquenio, la misma región concentró el $65 \%$ de la producción total a nivel nacional (Anuarios SERNAPESCA 2010-2014). Cabe destacar además que en Los Lagos se encuentra inscrito el 29\% de los 94.164 pescadores que, según el Registro de Pescadores Artesanales, existen formalmente a nivel nacional. Si en el cálculo se incluye la región de Aisén la cifra alcanza el 33\% (RPA 2015, SERNAPESCA).

${ }^{3}$ Si en 2005 existían 2053 centros de acuicultura en operación a nivel nacional (peces, moluscos y algas), el 56\% (1155) se encontraba en la región de Los Lagos. Una década más tarde, en 2014, la cifra a nivel nacional había aumentado a 3595 centros en operaciones, de los cuales el $61,5 \%$ (2247) se encontraba en Los Lagos (SERNAPESCA, anuarios estadísticos 2005 y 2014). En cuanto a productividad, Chile sigue siendo el segundo productor de salmones a nivel mundial -detrás de Noruega-, y un importante exportador de choritos o mejillón chileno. De las 1.214.439 toneladas de productos acuícolas cosechadas en 2014 , el 59,3\% se produjo en la región de Los Lagos y el $36,8 \%$ en la región de Aisén. Si solo se considera la producción de salmones y truchas (955.112 toneladas) tenemos que el $49 \%$ se produjo en Los Lagos y el $46 \%$ en Aisén (SERNAPESCA, 2014).

${ }^{4}$ He analizado esta cuestión en mi investigación doctoral, contrastando discursos del desarrollo provenientes de los principales actores que por entonces interaccionaban en el marco de la expansión de la industria salmonera en la región de Aisén (Saavedra, 2011).

${ }^{5}$ Grupo de discussion realizado en San Antonio, Calbuco, en marzo de 2012.

${ }^{6}$ Entrevista audiovisual a Juan Carlos C., STI de San Antonio Estero, Isla Quihua, Calbuco.

\footnotetext{
${ }^{7}$ Para complementar esta visión, lo mismo podría decirse de la regionalización de la pesca artesanal. Por cierto, el factor detonante de las medidas de zona contigua y en consecuencia de las tensiones derivadas de esta medida administrativa.

${ }^{8}$ Eso es demostrable con registros históricos y con datos de investigación reciente (memoria oral), donde se constata que la gran mayoría de los actuales habitantes de Guaitecas -como de Islas Huichas- tienen ascendencia del sur de Chiloé.

${ }^{9}$ Hasta 1981 , la comuna de Guaitecas no existía como tal y pertenecía administrativamente al Departamento de Castro en Chiloé.

${ }^{10}$ La declaración de Zonas Contiguas vía decreto supremo, es siempre parte de una coyuntura, es decir va a depender del estado de conservación de los recursos y de las "presiones" que ejerzan las organizaciones de pescadores artesanales. El último decreto exento (no 306) data del 25 de febrero de 2005, y estableció Zona Contigua para la extracción de erizos, el recurso base de la actual economía comercial de las comunidades bentónicas de Aisén.

${ }^{11} \mathrm{En}: \mathrm{http}: / / \mathrm{ww} w$.fondofomento.cl/faro/faroima/edicionanteriores/17/ articulo_4.htm.

${ }^{12}$ Registro etnográfico 3 de agosto de 2007, Puerto Aisén, diálogo con el dirigente Misael Ruiz.

${ }^{13}$ Entrevista a Lorena Taruman, pescadora artesanal de Puerto Aguirre [Islas Huichas], Coyhaique, Agosto 2007.

${ }^{14}$ Entrevista a dirigente demersal de Puerto Chacabuco (realizada en Vilcún), agosto 2007.

15 Incluso respecto de Quellón es probable que las relaciones (con la gente de Guaitecas) sean más estables estructuralmente. No debe descuidarse esa dimensión relacional muy condicionada por variables culturales-consanguíneas que anteceden a lo político. En una investigación etnográfica realizada entre 1998 y 2002, hemos demostrado con datos cualitativos (entrevistas) que tanto en Guaitecas como en Huichas existe una importante base de ancestros nacidos en el sur de Chiloé (Saavedra, 2002).

${ }^{16}$ Baso este análisis en las ideas recientemente desarrolladas por Macías \& González (2015).
} 


\section{Referencias bibliográficas}

Bitrán, E. (1989). "Proposición de un régimen de administración para las pesquerías chilenas". En VV.AA. El desafío pesquero chileno. La explotación racional de nuestras riquezas marinas. Santiago: Ediciones Pedagógicas Chilenas.

Bourdieu, P. (2003). Las estructuras sociales de la economía. Barcelona: Anagrama.

Escobar, A. (2008). Territories of Difference: Place, Movements, Life, Redes. Duke: Duke University Press.

García Canclini, N. (1990). Culturas híbridas. Estrategias para entrar y salir de la modernidad. México: Grijalbo.

Gelcich, S., Edward-Jones, G., Kaiser, M., \& Watson, E. (2005). "Using Discourses for Policy Evaluation: The Case of Marine Common Property Rights in Chile". Society and Natural Resources, № 18.

Godelier, M. (1990). Lo ideal y lo material. Madrid: Taurus.

Gudeman, S. \& Rivera, A. (1990). Conversations in Colombia: The Domestic Economy in Life and Text. Cambrigde: Cambridge University Press.

Hinkelammert, F. (2001). El nihilismo al desnudo. Los tiempos de la globalización. Santiago: LOM.

Lechner, N. (2006). La conflictiva y nunca acabada construcción del orden deseado. En Obras escogidas. Santiago: LOM.

Macías Vázquez, A. \& Alonso González, P. (2015). "Collective Symbolic Capital and Sustainability: Governing Fishing Communities in a Knowledge Economy". Marine Policy, № 53.

Mansilla, S., \& Rojas, E. (2007). "Caminando por la cornisa de este planeta llamado Chiloé: testimonio de Edward Rojas V., arquitecto". Alpha, № 25. Osorno.

Marín, A. \& Gelcich, S. (2012). "Gobernanza y capital social en el comanejo de recursos bentónicos en Chile: aportes del análisis de redes al estudio de la pesca artesanal". CUHSO, Vol. 22, № 1.

Navarro, M. (2014). Lógicas y dinámicas económico-culturales. Quellón y Las Guaitecas como escenarios de coproducción de diferencias y transformaciones. (Tesis de Magíster en Ciencias Sociales, mención Estudios de procesos y desarrollo de las sociedades regionales). Universidad de Los Lagos, Osorno.

Ostrom, E. (1990). Governing the Commons: The Evolution of Institutions for Collective Action. Cambrigde: Cambridge University Press.
Reyes, O., San Román, M., \& Moraga, M. (2011). "Archipiélago de los Chonos: nuevos registros arqueológicos y bioantropológicos en los canales septentrionales. Isla Traiguén, Región de Aisén". Magallania, Vol. 39, № 2.

Saavedra, G. (2011). Perspectivas culturales del desarrollo en las costas australes de Chile. Aproximación antropológica a las persistencias y transformaciones de las economías de pesca artesanal en el litoral de Aisén. (Memoria para optar al grado de doctor, Facultad de Ciencias Políticas y Sociología). Universidad Complutense de Madrid.

(2002). Paso al Sur: el litoral norte de Aisén: poblamiento, etnografía y desarrollo. (Memoria de título para optar al grado de antropólogo social). Universidad de Chile.

Sahlins, M. (1988). Islas de historia: la muerte del capitán Cook,. Metáfora, antropología e historia. Barcelona: Gedisa.

Servicio Nacional de Pesca (2005). Evaluación técnica y económica del impacto de las Áreas de Manejo y Explotación de Recursos Bentónicos. Valparaíso: Departamento de Pesca Artesanal.

Servicio Nacional de Pesca y Acuicultura (2015). RPAPescadores y embarcaciones. Registro Pesquero Artesanal. Valparaíso: Departamento de Pesca Artesanal.

(2005-2014). Anuario estadístico de pesca. Valparaíso.

Skewes, J. C., Álvarez, R. \& Navarro, M. (2012) "Usos consuetudinarios, conflictos actuales y conservación en el borde costero de Chiloé insular". Magallania, Vol. 40, № 1. Punta Arenas.

Urbina, R. 1988. "Chiloé, foco de emigraciones". Colección Terra Nostra, № 12. Santiago: Instituto de Investigaciones del Patrimonio Territorial de Chile, Universidad de Santiago de Chile.

Valencia, G. (2009). "El oficio delsociólogo. La imaginación sociológica”. En Tapia, L. (coord.). Pluralismo epistemológico. Bolivia: Muela del Diablo Editores, Couna, CLACSO, CIDES-UMSA.

Zelada, S \& Park, J. (2013). "Análisis crítico de la Ley Lafkenche (n 20.249): El complejo contexto ideológico, jurídico, administrativo y social que dificulta su aplicación”. Universum, Vol. 28, № 1. Talca. Disponible en: http://www.scielo.cl/scielo.php?pid=S071823762013000100004\&script=sci_arttext Fecha de consulta: 25 de enero de 2016. 
